\title{
DDA in fluid-structure problems for the study of gravity dam failure
}

\author{
Sami Kaidi* — Abdellatif Ouahsine* — Mohamed Rouainia** \\ Hassan Smaoui*** \\ * UTC, Laboratoire Roberval UMR-CNRS \\ BP 62529, 60206 Compiègne cedex, France \\ ** School of Civil Engineering and Geosciences \\ Newcastle University \\ Newcastle upon Tyne NE1 7RU, United Kingdom \\ *** UTC-CETMEF, Laboratoire Roberval UMR-CNRS 6253 \\ BP 20529, 60206, Compiègne, France
}

\begin{abstract}
In this paper, we present a $2 D$ coupled fluid-structure interaction procedure to assess the stability of a cracked gravity dam against increasing water level. In this procedure the structure is assumed to be a discontinuous deformable solid containing pre-existing cracks. Thus, the Discontinuous Deformation Analysis DDA method is used to study the solid discontinuous medium, and the continuum finite element flow model to calculate the hydrostatic forces corresponding to the water level. The contact constraints between discrete blocks are imposed through an implicit augmented Lagrangian format. Numerical results show the potential of the proposed coupled model to quantify the direct influence of the nature and location of the internal cracks on the overall stability of common gravity dams.

RÉSUMÉ. Dans ce travail, une procédure de couplage fluide-structure $2 D$ est mise en auvre pour étudier la stabilité d'un barrage poids fissuré et soumis à la pression hydrostatique due à l'augmentation brusque du niveau d'eau. Cette modélisation tient compte de la nature et de la position de la fissure interne du barrage. Le module solide est basé sur la méthode de l'analyse des déformations discontinues (DDA). Les forces mises en jeu dans ce module proviennent d'un module fluide qui fournit la pression hydrostatique. Les simulations ont mis en évidence l'importance de la nature de la fissure ainsi que sa position sur la résistance de ce type de barrage.

KEYWORDS: fluid-structure coupling, DDA method, DEM, gravity dam, stability, crack.

MOTS-CLÉS : interaction fluide-structure, DDA, DEM, barrage poids, stabilité, fissure.
\end{abstract}

DOI:10.3166/EJCM.19.533-546 (c) 2010 Lavoisier, Paris

EJCM - 19/2010. Fluid-structure interaction, pages 533 to 546 


\section{Introduction}

Several coupled methods have been proposed to simulate fluid-structure problems subjected to static and dynamic forces. Coupled continuum approaches using the finite element method (FEM) (Zienkiewicz et al., 1977) to represent the structure and the boundary element method (BEM) to represent the fluid have been successfully for many fluid-structure systems (von Estorff et al., 1991). However, the use of continuum approaches to model materials with discrete discontinuities has met with only limited success. A number of discontinuum-based approaches have been developed in the disciplines of geomechanics, petroleum, chemical and environmental engineering. For example the Distinct Element Method (DEM), first proposed and developed by (Cundall, 1980; Cundall, 1988; Cundall et al., 1979), is used for both deformable and rigid blocks with deformable contact joints. An explicit force-based scheme is employed in the formulation of the DEM which requires an artificial introduction of a damping (Bobet et al., 2009; Hart, 1993). More recently, the Discontinuous Deformation Analysis (DDA) has been proposed by Shi (Shi et al., 1985; Shi, 1988; Shi, 1993) for the analysis of discontinuous block systems. The DDA parallels the FEM in that both are displacement-based methods. This formulation overcomes the problem of energy dissipation when DEM is applied without an artificial damping (Wang et al., 1996). Many extensions to the DDA method have been proposed consisting of improving the contact algorithms, adding structural calculations using sub-blocks and as including block-fracturing (Lin et al., 1996; Hatzor et al., 2001; MacLaughlin et al., 2003). DDA has been further extended by (Jing et al., 2001; Rouainia et al., 2006) to include coupled solid-flow problems.

In this paper a framework for modelling deformable discontinuous media using the DDA method is coupled with a continuum formulation using the FEM to predict the distribution of fluid pressures. In such a system there is considerable flexibility in defining initial block and fluid geometries. Block contact constraints are imposed through an implicit augmented Lagrangian format (Lin et al., 1996). The proposed framework has been used to predict the stability of gravity dams subjected to hydrostatic forces. The stability is assessed by the DDA/FEM approach in the presence of pre-existing internal cracks in dams and following a sudden increase in water level. These cracks are often caused by piping, earthquakes (Pekau et al., 2004), aging and failure of construction materials. If the variation in water level is to increase, then it is the potential of ultimate failure will also increase.

\section{Discontinuous deformation analysis}

DDA is similar to FEM in that both are displacement-based methods that attempt to minimize the total potential energy of system to satisfy the equilibrium condition for quasi-static problems. However, the DDA has a distinct advantage over the FEM in its ability to capture large deformations along discontinuities and large block movements. In the DDA formulation, the vector of variables $\{\boldsymbol{d}\}$ associated with an individual block has six degrees of freedom : 


$$
\boldsymbol{d}=\left\{u_{0}, v_{0}, \theta, \varepsilon_{x x}, \varepsilon_{y y}, \varepsilon_{x y}\right\}
$$

where $u_{0}, v_{0}$ represent the rigid body translation at a specific point $\left(x_{0}, y_{0}\right)$ in the DDA block, $\theta$ the rotation about the centroid, and $\varepsilon_{x x}, \varepsilon_{y y}, \varepsilon_{x y}$ are the normal and shear strains in the block, respectively. In two dimensional space, the first order approximation of the displacement $(u, v)$ at any point $(x, y)$ of a given block $i$, takes the following form :

$$
\left\{\begin{array}{l}
u \\
v
\end{array}\right\}=\left[T_{i}\right] \boldsymbol{d}
$$

where $\left[T_{i}\right]$ is the transformation matrix given as follows :

$$
T_{i}=\left[\begin{array}{cccccc}
1 & 0 & -\left(y-y_{o}\right) & \left(x-x_{o}\right) & 0 & \left(y-y_{o}\right) \\
0 & 1 & -\left(x-x_{o}\right) & 0 & \left(y-y_{o}\right) & \left(x-x_{o}\right)
\end{array}\right]
$$

In the DDA method, the equilibrium equations are provided by the principle of potential energy minimization. In general, the potential energy for a system containing $N$ blocks may be expressed as :

$$
\pi=\sum_{i=1}^{N}\left(\frac{1}{2}[\varepsilon]^{T}[\boldsymbol{\sigma}] d x d y\right)+C
$$

where the first term in Equation [4] represents the total deformation energy of $N$ blocks and the second term is the total work done by the external forces on the blocks including point and gravity loads, block-to-block contact forces, initial stresses, inertia forces, and boundary loads.

Similar to the finite element approach, the minimization of the potential energy, $\pi$, for block $i$ with respect to its displacement variables, is given by the following six equations :

$$
\frac{\partial \pi_{i}}{\partial \boldsymbol{d}_{j}}=\boldsymbol{k}_{i j} d_{j}-\boldsymbol{f}_{j}=0, \text { for } j=1, \cdots 6
$$

where $\boldsymbol{d}_{j}$ contains the six deformation variables associated with block $i$. For the complete system of $N$ blocks, the global equilibrium equation can then be written in matrix form as follows : 


$$
\left(\begin{array}{ccccc}
\boldsymbol{k}_{11} & \boldsymbol{k}_{12} & \boldsymbol{k}_{13} & \ldots & \boldsymbol{k}_{1 n} \\
\boldsymbol{k}_{21} & \boldsymbol{k}_{22} & \boldsymbol{k}_{23} & \ldots & \boldsymbol{k}_{2 n} \\
\boldsymbol{k}_{11} & \boldsymbol{k}_{12} & \boldsymbol{k}_{13} & \ldots & \boldsymbol{k}_{3 n} \\
\ldots & \ldots & \ldots & \ldots & \ldots \\
\boldsymbol{k}_{n 1} & \boldsymbol{k}_{n 2} & \boldsymbol{k}_{n 3} & \ldots & \boldsymbol{k}_{n n}
\end{array}\right)\left(\begin{array}{c}
\boldsymbol{d}_{1} \\
\boldsymbol{d}_{2} \\
\boldsymbol{d}_{3} \\
\ldots \\
\boldsymbol{d}_{n}
\end{array}\right)=\left(\begin{array}{c}
\boldsymbol{f}_{1} \\
\boldsymbol{f}_{2} \\
\boldsymbol{f}_{3} \\
\ldots \\
\boldsymbol{f}_{n}
\end{array}\right)
$$

where $f_{i}$ is a $6 \times 1$ vector of forces acting on block $i$ and $d_{i}$ contains the variables associated with block $i$. The off-diagonal sub-matrices $\boldsymbol{k}_{i j}(i \neq j)$ contain the stiffness components associated with the contact between blocks $i$ and $j, \boldsymbol{k}_{i i}$ refers also to the components of the material stiffness of block $i$. It should be noted that all sub-matrices have dimensions $6 \times 6$.

\section{Contact formulation}

Three formulations have been used to model the contact between blocks in the DDA method. The penalty method is the first method which was originally used by Shi (1988) to enforce contact constraints at block interfaces and to ensure the nonpenetration condition between blocks. This method has proved to be effective in many areas of numerical modeling, and it has advantages including, the number of equations to be solved remains the same despite the additional contact forces and The stiffness matrix for the system with contact can be easily obtained from the original matrix by simply adding a contact component to the elements.

The limitation with this method however, is the choice of the penalty number, since the solution obtained depends significantly on this number. A second method that may be used to calculate contact forces in the DDA method is the method of Lagrange multiplier method. The advantage of this method is the Lagrange multiplier represents a contact force which can be calculated directly. However, this method suffers from a major computational disadvantage in the sense that as the number of governing equations is increased by the Lagrange multipliers the solution becomes computationally prohibitive.

In the present study, the contact between blocks has been modelled using the Augmented Lagrangian formulation. This method is preferable since it contains aspects of both the penalty method and the classical Lagrange multiplier method. In this formulation, the total energy is given by the following expression :

$$
\pi=\lambda \delta+\frac{1}{2} p \delta^{2}
$$

where the first term accounts for the work done by the contact forces between the blocks, while the second term represents the elastic potential energy associated with the contact between the blocks (contact modelled as a spring under tension to enforce the non-penetration condition). The parameter $\delta$ is used to represent the gap between 


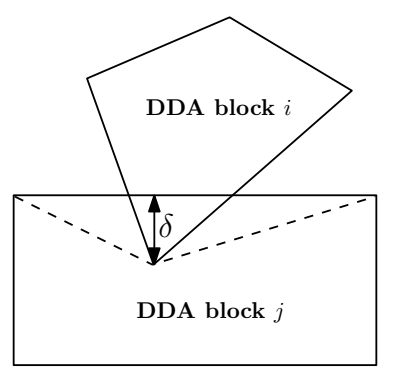

Figure 1. Schematic representation of the block-into- block penetration condition

the contacting blocks. This can be expressed as a function of the displacement vectors of two DDA blocks (see Figure 1).

An iterative procedure, based on the Augmented Lagrangian method, is used to calculate the magnitude of the contact forces between the DDA blocks. The fundamental concept underlying this method is that both, a penalty number, $p$, and a Lagrange multiplier, $\lambda^{*}$ (representing the contact force $\lambda$ ) are used. An iterative process is used to calculate the first order update of the Lagrangian multiplier, as follows

$$
\lambda_{k+1}^{*}=\lambda_{k}^{*}+p \delta
$$

where the superscript $(k)$ refers to the $k$ th local iteration number. The iterative process is completed if the convergence criterion $\delta=\delta_{m}$ is satisfied, where $\delta_{m}$ is a minimum tolerance of the distance of penetration.

\section{Fluid-structure coupling}

The coupling model between the fluid and structure occurs at the interface between both domains and is denoted by the dashed line presented in Figure 2. The coupling procedure is applied at the interface $\Gamma_{c}$ between the fluid and the structure, it consists on the exchange, of the pressure from the fluid to the structure. The transfer of the data, takes a simple way by the direct calculation of the pressure, according to the height of the water level, The procedure used for coupling, is based on an explicit algorithm. At each time step $t_{n}$, the height of the water is increased and the corresponding pressure $P_{n}$ calculated. $P_{n}$ may then be converted to an external load applied across the borders of the structure. The procedure repeats several times until arriving at the maximum height possible prior to dam failure. To calculate hydrostatic pressure, the following formula is used :

$$
P_{z}=P_{0}+\rho_{f} g z
$$



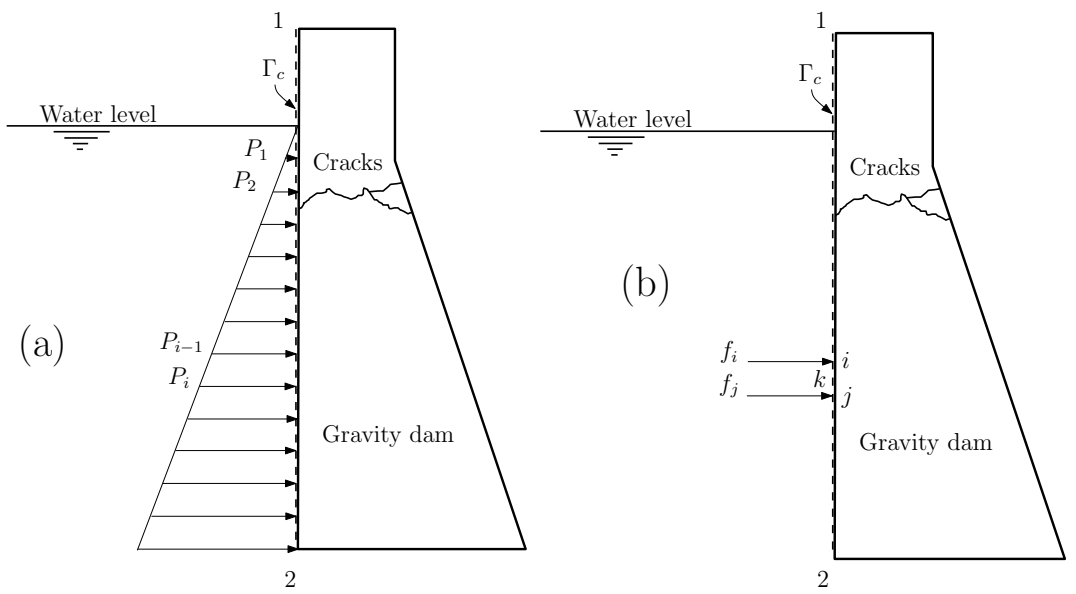

Figure 2. Simplified diagrams of (a) pressure distribution on dam and (b) forces distribution on dam

where $P_{0}$ is an atmospheric pressure, $g$ the acceleration of gravity, $\rho_{f}$ the density of water and $z$ is the height of the water.

It is assumed that $i$ and $j$ are nodes of a finite element $k$. Computing the total hydrodynamic forces applied to the length of the segment to a high accuracy requires carrying out several stages. The first stage assumes the distribution of pressure is linear, and is used to find the force $f_{i}, f_{j}$ applied to every node using the following equations :

$$
\begin{aligned}
f_{i} & =f_{\text {avg }} \frac{P_{i}}{P_{i}+P_{j}} \\
f_{j} & =f_{\text {avg }} \frac{P_{j}}{P_{i}+P_{j}}
\end{aligned}
$$

where $f_{\text {avg }}=\left(P_{i}+P_{j}\right) d / 2$ is the average force caused by pressures $P_{i}$ and $P_{j}$ and $d=\left[\left(x_{j}-x_{i}\right)^{2}+\left(y_{j}-y_{i}\right)^{2}\right]^{1 / 2}$ is the distance between node $i$ and node $j$ for the finite element $k$ (see Figure 2)

Once the nodal forces have been calculated, the second stage is carried out. This involves calculating the total force acting along the DDA block vertices as follows : 


$$
\begin{aligned}
& F_{1 x}=\sum_{i=1}^{n} f_{i} n_{x}\left(\frac{d_{2}}{d_{1}+d_{2}}\right), \quad F_{1 y}=\sum_{i=1}^{n} f_{i} n_{y}\left(\frac{d_{2}}{d_{1}+d_{2}}\right) \\
& F_{2 x}=\sum_{i=1}^{n} f_{i} n_{x}\left(\frac{d_{1}}{d_{1}+d_{2}}\right), \quad F_{2 y}=\sum_{i=1}^{n} f_{i} n_{y}\left(\frac{d_{1}}{d_{1}+d_{2}}\right)
\end{aligned}
$$

where $n$ denotes the total number of finite element fluid fluid nodes along the edge, $n_{x}$ and $n_{y}$ are the edge directions and $d_{1}$ and $d_{2}$ are the distances from a given node to edge 1 and 2 of a DDA block, respectively. Once the horizontal and vertical components of the forces $F_{1}$ and $F_{2}$ are determined, they are added to the structural loads and applied as boundary conditions. Mostly, these equivalent forces produce a change in the configuration of the solid block orientation, i.e. they induce block rotations, translations and/or straining.

\section{Numerical examples}

\subsection{Example 1}

In this numerical test, the strength of a cracked dam against increasing water level is assessed. The presence of cracks causes dams to become very dangerous with risk of collapse if fluid pressure loading becomes too high. To insure the safety of these structures, it is necessary to calculate the maximum load that can be supported by the dam, given to the nature and orientation of cracking.

In the following example, the pressure exerted upon the dam is assumed to be purely hydrostatic, and the dam itself constructed of concrete with known properties. These properties are as follows ; Young's modulus $E=50 \mathrm{GPa}$, Poisson's ratio $\nu=$ 0.2 and a concrete density $\rho_{s}=2500 \mathrm{Kg} / \mathrm{m}^{3}$. Fluid density is assumed to be $\rho_{f}=$ $1000 \mathrm{Kg} / \mathrm{m}^{3}$ and it is also assumed that all joints have a friction angle $\phi=30^{\circ}$ and cohesion $c=300 \mathrm{kPa}$. The initial penalty number is taken $\delta=5 \times 10^{6}$. The geometrical measurements of the studied dam, as well as the location of the pre-existing cracks are shown in Figure 3.

In order to estimate the maximum water pressure supported by the dam, the water level above the cracked area is gradually increased until structural failure occurs. Results from this process show that the pressure limit is met when the water reaches a height of $7 \mathrm{~m}$ above the cracked area. This corresponds to $170 \mathrm{kPa}$.

Figure 4 shows the horizontal and vertical displacements of the two blocks over the course of 12 seconds, with reference to their initial centre of gravity. At the start of the simulation, the dam was stable despite the existence of internal cracks, possibly explained by the effect of inter block cohesion. The oscillations exhibit ed in the fi- 
gure are likely due to the irregular geometry of the cracks themselves and the friction generated as the blocks move relative to one another.

Figure 5 shows the evolution of block movements during the failure, where the corresponding velocities are presented in Figure 6.

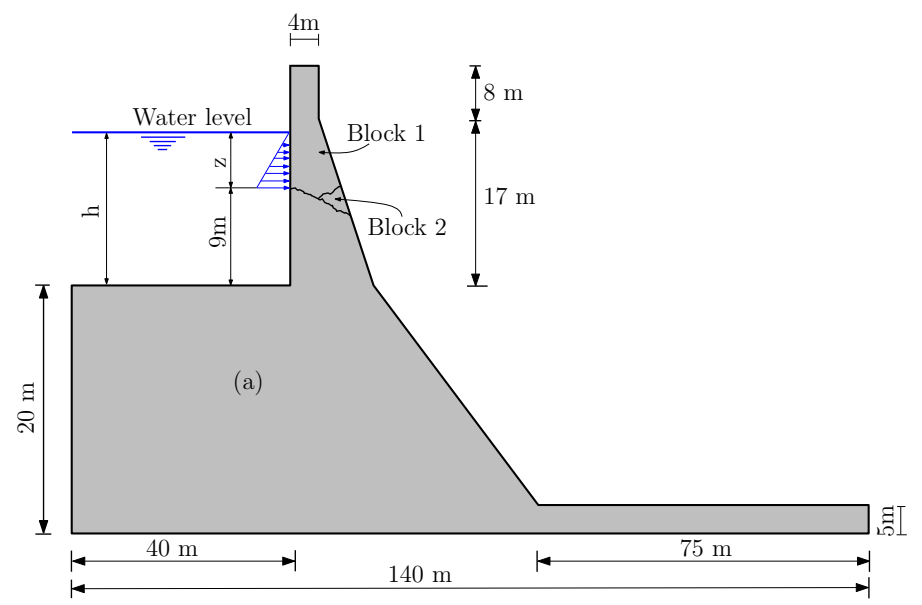

Figure 3. Example 1 : Schematic representation of the studied dam with the location of cracks

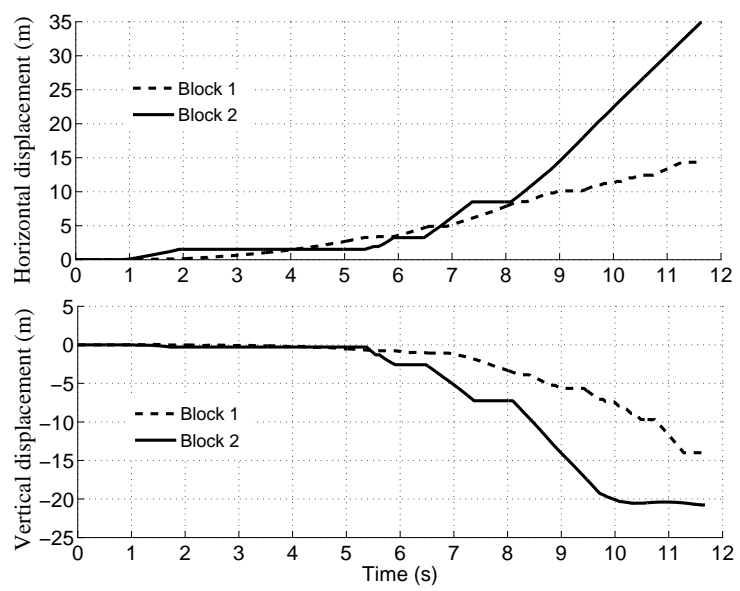

Figure 4. Example 1 : horizontal and vertical displacement at the gravity centre of the blocks 


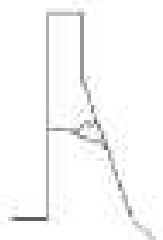

$\mathrm{t}=0 \mathrm{~s}$

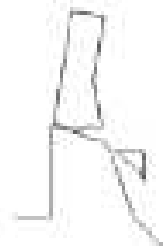

$\mathrm{t}=3.75 \mathrm{~s}$

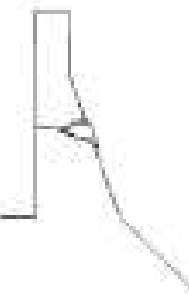

$\mathrm{t}=1.25 \mathrm{~s}$

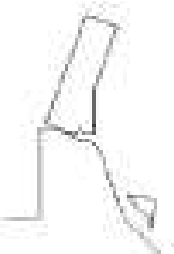

$$
\mathrm{t}=5 \mathrm{~s}
$$

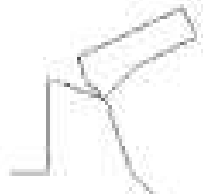

$\mathrm{t}=7.5 \mathrm{~s}$

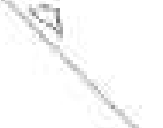

$\mathrm{t}=8.75 \mathrm{~s}$ $\mathrm{t}=6.25 \mathrm{~s}$

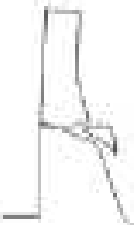

$\mathrm{t}=2.5 \mathrm{~s}$
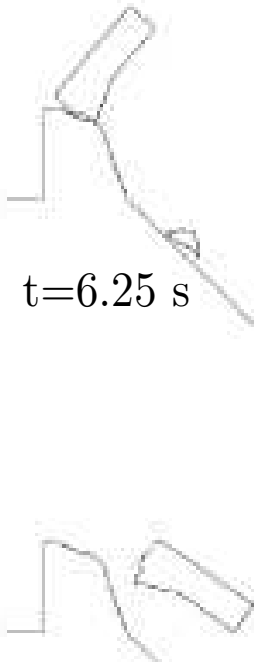

$\mathrm{t}=9.88 \mathrm{~s}$
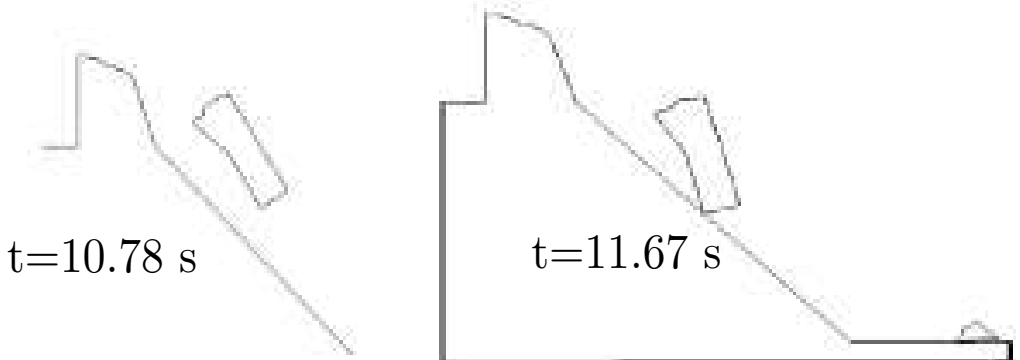

Figure 5. Example 1 : failure behaviour of the gravity dam 

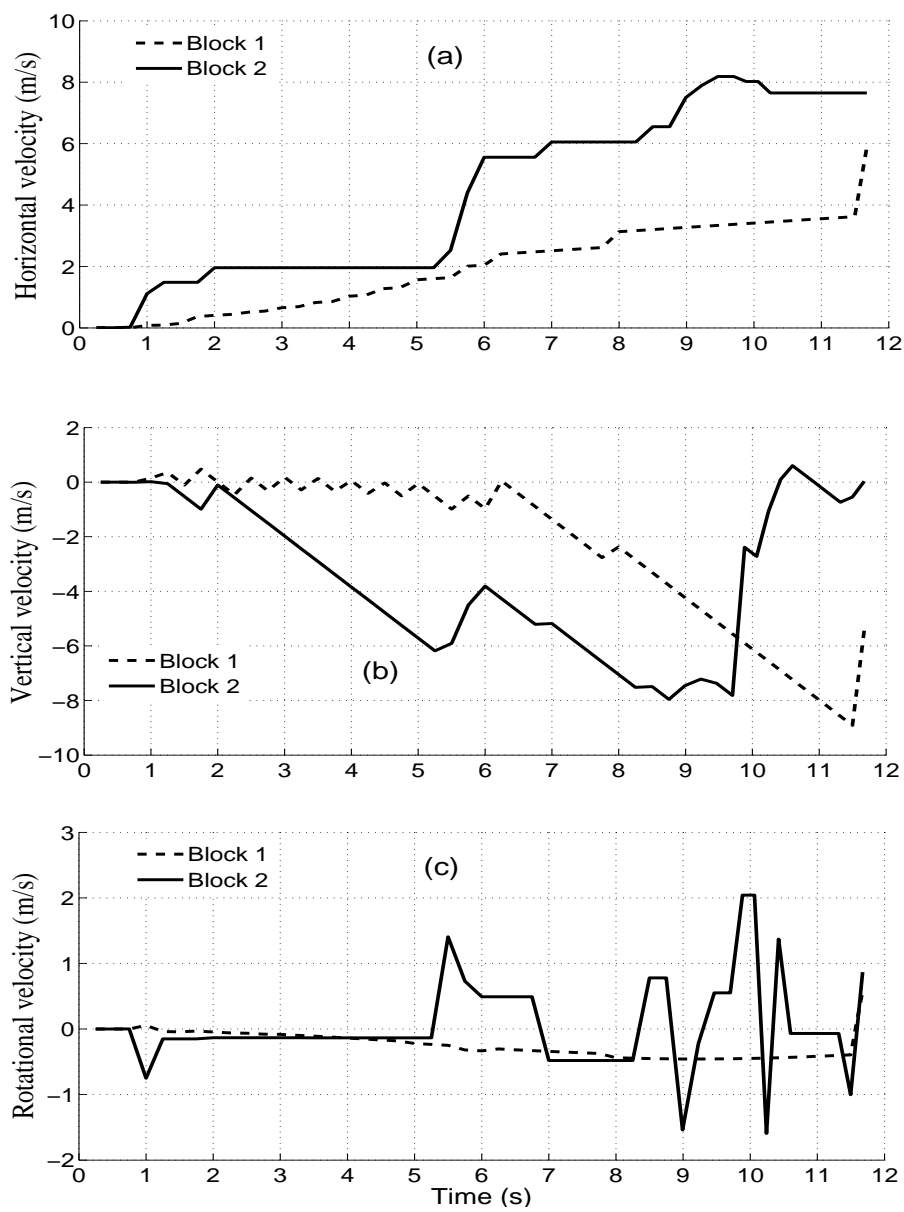

Figure 6. Velocities at the gravity centre of two DDA blocks : (a) horizontal, (b) vertical and (c) rotational

\subsection{Example 2}

In this second example, the importance of the position of the cracked area in relation to the total height of the dam is explored. Figure 4.2 shows the shape of the crack and its location in the dam. The material properties are kept the same as in the previous example and the water level is gradually increased to test the strength of the dam in the presence of a crack located at a lower level than that of the first example.

Figure 4.2 shows that the failure of the dam occurs earlier in time when the crack is deeper. In this example the crack depth is $z=17.05 \mathrm{~m}$, which corresponds to $h=$ $20.55 \mathrm{~m}$. This confirms the direct influence of the nature and location of the crack on 
the stability of the dam. It can be seen that the dam fails in two phase. The first phase is constrained between 0 and $2 \mathrm{~s}$ and represents a sliding failure. Small movements are noted in blocks 1 and 3 due to the effect of the weight of the large block 2 and also of the hydrostatic load. The second phase (from 2 s until the end of the simulation) represents the total dam failure. In this stage all blocks are moving continuously, the impact of one block with another is shown by the sudden change of displacement and/or velocity decreases.

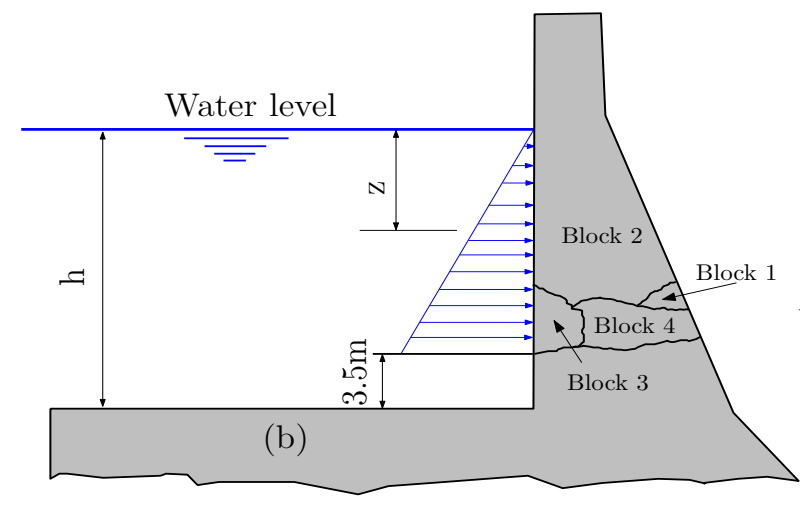

Figure 7. Schematic representation of the studied dam with the location of cracks
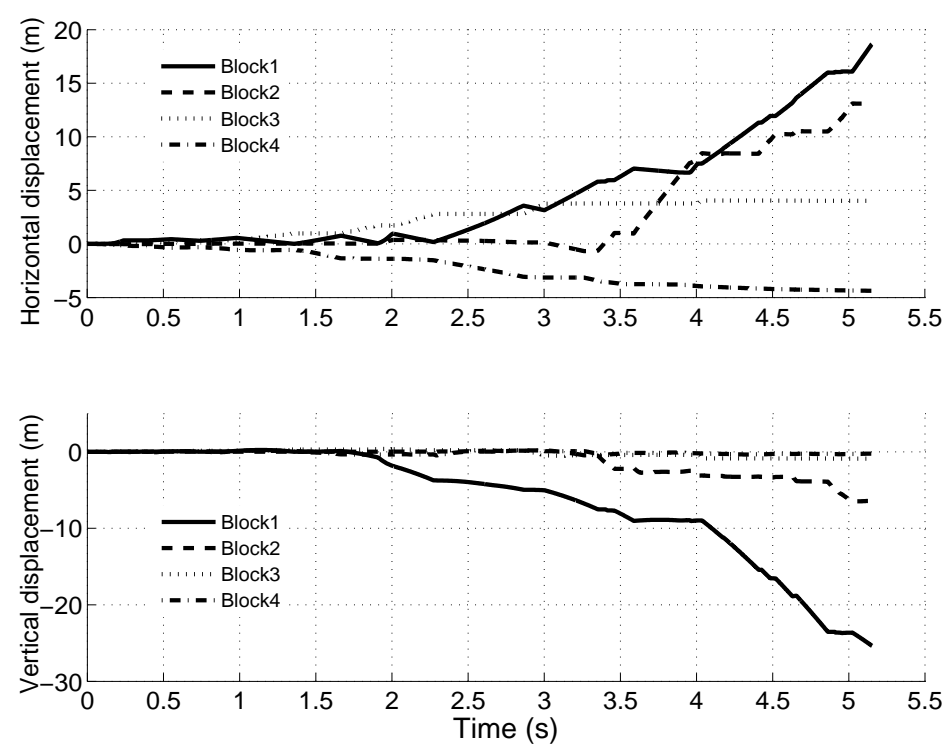

Figure 8. Displacements at the centre of gravity of the DDA blocks 
544 EJCM - 19/2010. Fluid-structure interaction
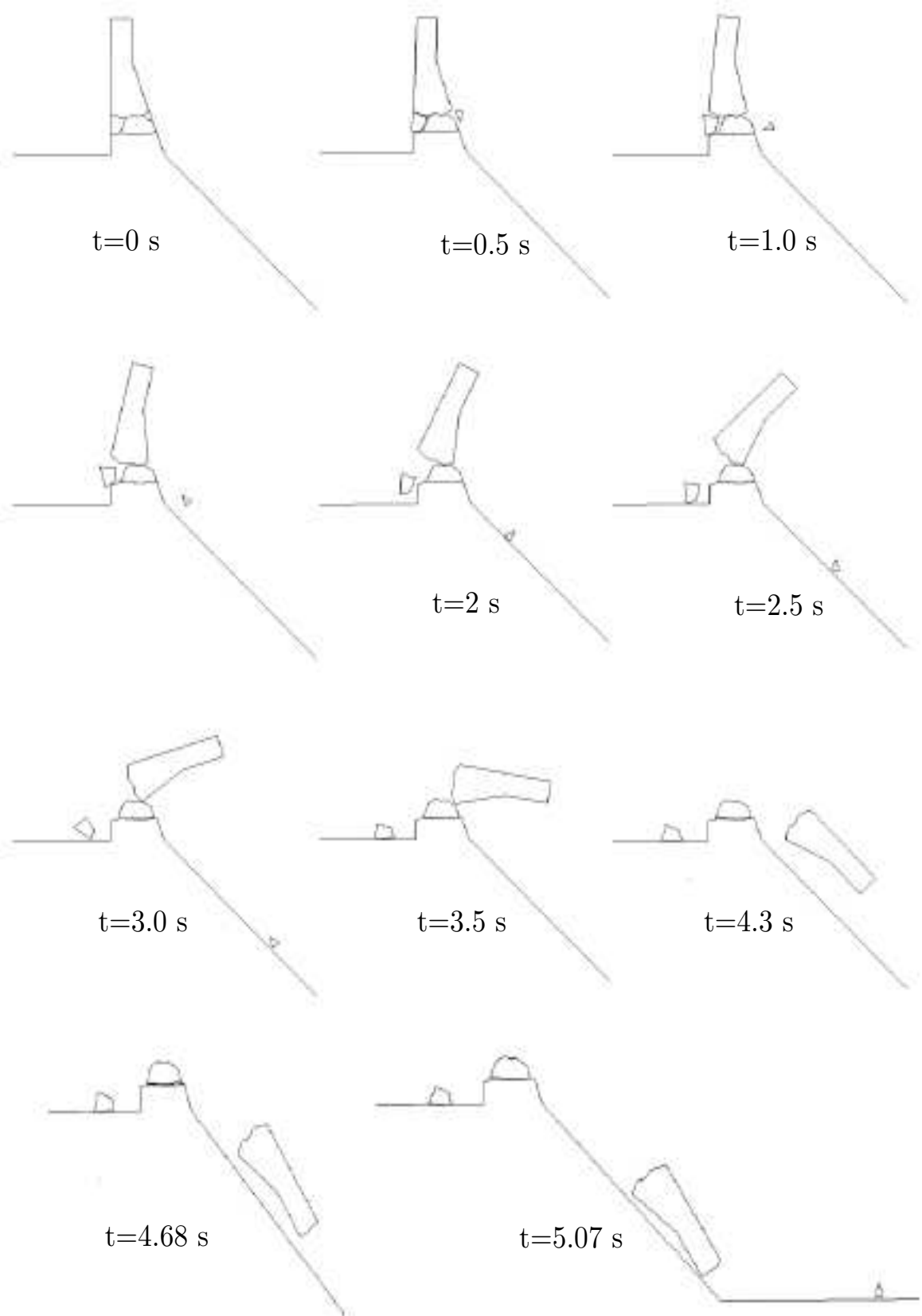

Figure 9. Example 2 : failure behaviour of the gravity dam 


\section{Conclusion}

A coupled fluid-solid numerical model is used to study the structural stability of a gravity dam against a sudden increase of water level. The structure is partially cracked and formed of discrete elements (blocks) which are likely to separate during failure. Using the DDA method, as an alternative to conventional methods such as FEM and DEM, contact and friction have been explored as well as cohesion between the blocks. The simulation predictions have shown the ability of the DDA method to model cracked dam problems and study stability. Results show that the safety of a given dam may be ensured for a known crack shape providing that the level of water remains below the critical level computed by the presented model.

\section{References}

Bobet A., Fakhimi A., Johnson S., Morris J., Tonon F., Yeung M., « Numerical Models in Discontinuous Media : Review of Advances for Rock Mechanics Applications », Journal of Geotechnical and Geoenvironmental Engineering, vol. 135, n 11, p. 1547-1561, 2009.

Cundall P., A generalized distinct element program for modeling jointed rock, Report PCAR1-80 n² 265, European Research Office, US Army Corps of Engineers, septembre, 1980.

Cundall P., « Formulation of a three-dimensional distinct element model : a scheme to detect and represent contacts in a system composed of many polyhedral blocks », Int J Rock Mech Min Sci Geomech Abstr, vol. 25, n³, p. 107-116, 1988.

Cundall P., Strack O., « A discrete numerical model for granular assemblies », Geotechnique, vol. 29, p. 4765, 1979.

Hart R. D., « An Introduction to Distinct Element Modelling for Rock Engineering », 7th International Congress on Rock Mechanics, vol. 3, Rotterdam : Balkema, Aachen, Germany, p. 1881-1892, 1993.

Hatzor Y., Feintuch A., « The validity of dynamic block displacement prediction », Int J Rock Mech Min Sci, vol. 38, p. 599-606, 2001.

Jing L., Ma Y., Fang Z., « Modeling of fluid flow and solid deformation for fractured rocks with discontinuous deformation analysis (DDA) method », Int J Rock Mech Min Sci Geomech Abstr, vol. 38, n 3, p. 343-355, 2001.

Lin C., Amadei B., Joseph J., Jerry D., « Extensions of discontinuous deformation analysis for jointed rock masses », Int J Rock Mech Min Sci, vol. 33, n 7, p. 671-694, 1996.

MacLaughlin M., Berger E., Doolin D., « A decade of DDA validation », Proceedings the sixth International Conference on analysis of discontinuous deformation, Norway, p. 1331, 2003.

Pekau O., Cui Y., « Failure analysis of fractured dams during earthquakes by DEM », Engineering Structures, vol. 26, p. 1483-1502, 2004.

Rouainia M., Lewis H., Pearce C., Bicanic N., Couples G., Reynolds M., « Hydrogeomechanical modelling of Seal behaviour in overpressured basins using discontinuous deformation analysis », Engineering Geology, vol. 82, n 4, p. 222-233, 2006.

Shi G., Discontinuous deformation analysis : a new numerical model for statics and dynamics of block systems, Ph.d thesis, University of California, Berkeley, 1988. 
546 EJCM - 19/2010. Fluid-structure interaction

Shi G., Block system modeling by discontinuous deformation analysis, Computation Mechanics, Boston, USA, 1993.

Shi G., Goodman R. E., « Two-dimensional discotinuous deformation analysis », Int. J. Numer. Analyt. Meth. Geomech, vol. 9, n 6, p. 541-556, 1985.

von Estorff O., Antes H., « On FEM-BEM coupling for fluid-structure interaction analyses in the time domain », Int J Num Meth Engng, vol. 31, p. 1151-1168, 1991.

Wang C., Chuang C., Sheng J., « Time integration theories for the DDA method with finite element meshes », 1st Int. Forum on Discontinuous Deformation Analysis (DDA) and Simulations of Discontinuous Media, Albuquerque, p. 263-287, 1996.

Zienkiewicz O., Kelly D., Bettess P., « The coupling of the finite element method and boundary solution procedures », Int J Num Meth Engng, vol. 11, p. 355-376, 1977. 